\title{
Erratum to: Iron isotope variations in spinel peridotite xenoliths from North China Craton: implications for mantle metasomatism
}

\author{
Xinmiao Zhao $\cdot$ Hongfu Zhang $\cdot$ Xiangkun Zhu \\ Suohan Tang $\cdot$ Yanjie Tang
}

Published online: 12 January 2010

(C) Springer-Verlag 2010

\section{Erratum to: Contrib Mineral Petrol}

\section{DOI 10.1007/s00410-009-0461-y}

Unfortunately, the corresponding author "Xinmiao Zhao" has been missed out in the second affiliation. The correct affiliation details are given below:

\section{Zhao $(\bowtie) \cdot H$. Zhang $\cdot$ Y. Tang}

State Key Laboratory of Lithopheric Evolution, Institute of Geology and Geophysics, Chinese Academy of Sciences, P.O. Box 9825, 100029 Beijing, China e-mail: xinmiao312@mail.iggcas.ac.cn

X. Zhao $\cdot$ X. Zhu $(\bowtie) \cdot S$. Tang

Laboratory of Isotopic Geology, MLR, Institute of Geology, Chinese Academy of Geological Sciences, 100037 Beijing, China

e-mail: xiangkun@cags.net.cn

The online version of the original article can be found under doi:10.1007/s00410-009-0461-y.

X. Zhao $(\bowtie) \cdot$ H. Zhang · Y. Tang

State Key Laboratory of Lithopheric Evolution,

Institute of Geology and Geophysics,

Chinese Academy of Sciences,

P.O. Box 9825, 100029 Beijing, China

e-mail: xinmiao312@mail.iggcas.ac.cn

X. Zhao $\cdot$ X. Zhu $(\bowtie) \cdot$ S. Tang

Laboratory of Isotopic Geology, MLR, Institute of Geology,

Chinese Academy of Geological Sciences,

100037 Beijing, China

e-mail: xiangkun@cags.net.cn 